\title{
Effect of Counterions on Dissolution of Amorphous Solid Dispersions Studied by
}

\section{Surface Area Normalized Dissolution}

\author{
Yinshan Chen ${ }^{1, *}$, Joseph W. Lubach ${ }^{1}$, Shijia Tang ${ }^{1}$, Ajit S. Narang ${ }^{1}$ \\ Small Molecule Pharmaceutical Sciences, Genentech Inc.
}

1 DNA Way, South San Francisco, CA 94080, U.S.A.

Corresponding author:

Yinshan Chen

Phone: +16504520479

E-mail: chen.yinshan@gene.com 


\section{Supporting Figures}
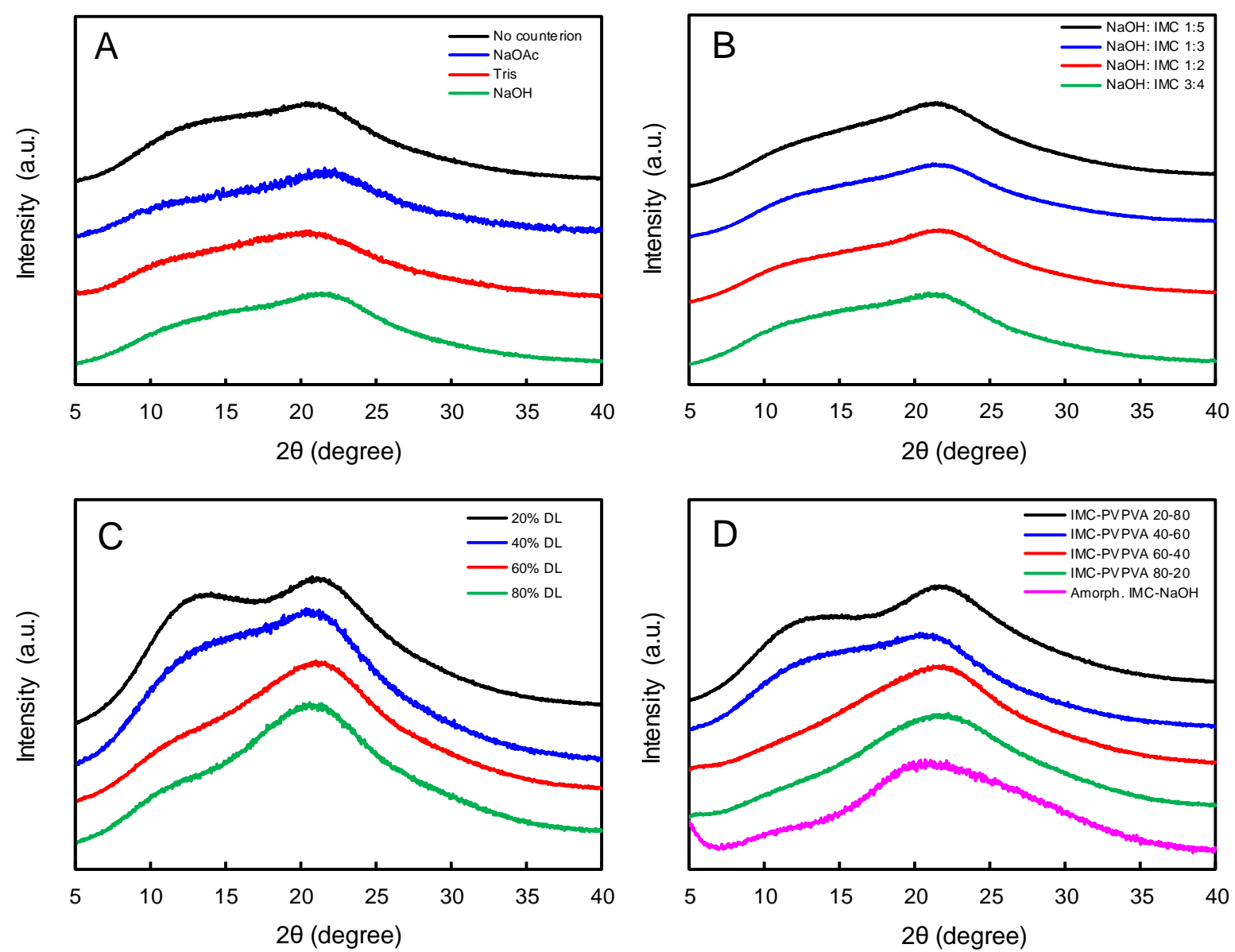

Figure S1. PXRD of ASD by rotary evaporation prior to IDR measurement. (A) IMC-PVPVA 40-60 (w/w) ASD containing different bases. The base was at 1:1 molar ratio to IMC. (B) IMC-PVPVA 40-60 (w/w) ASD containing $\mathrm{NaOH}$ at different $\mathrm{NaOH}$ : IMC molar ratios. (C) IMC-PVPVA ASDs at different IMC loadings without counterions. (D) IMC-PVPVA ASDs at different IMC-PVPVA weight ratios with $\mathrm{NaOH}$ at 1:1 molar ratio to IMC. 


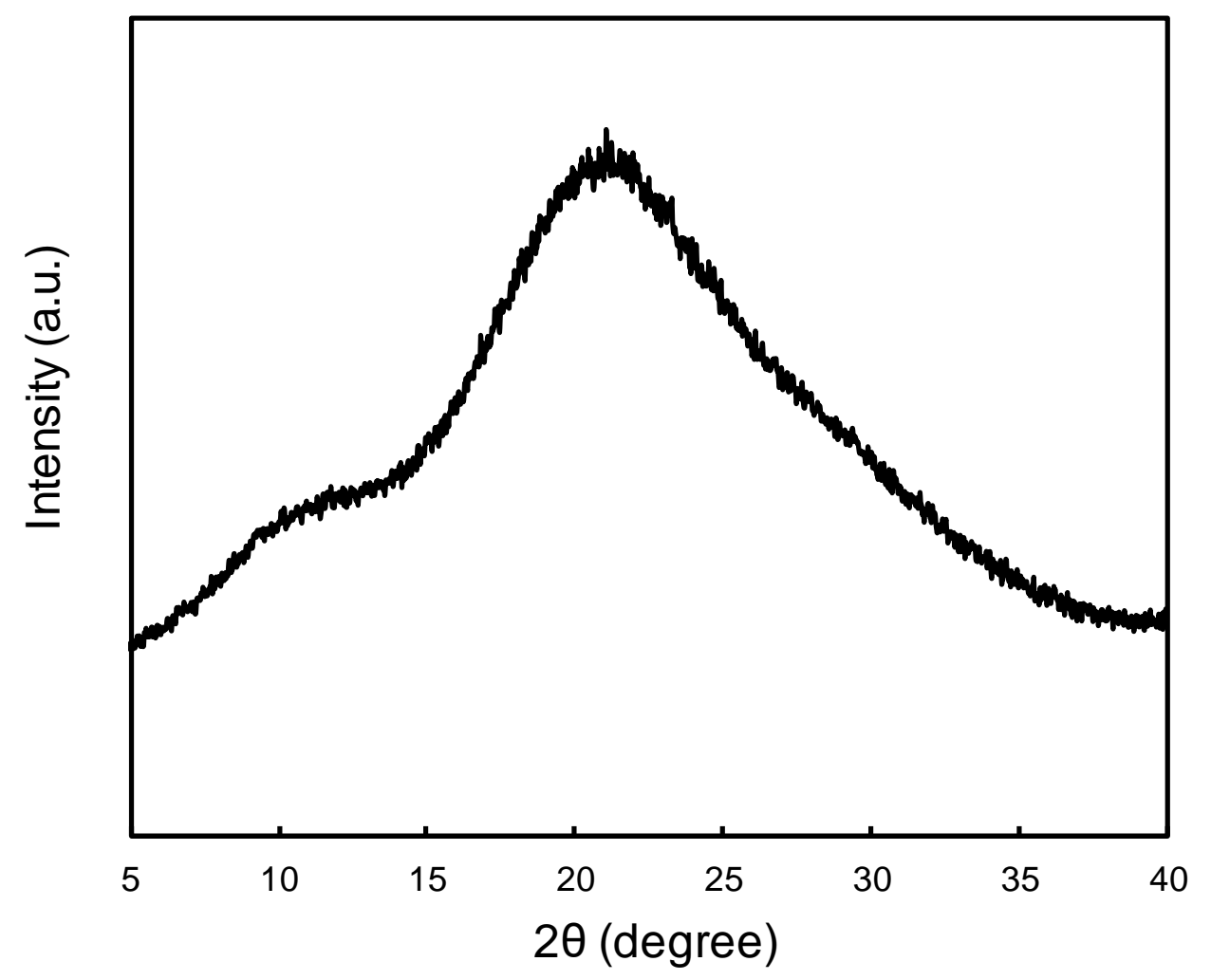

Figure S2. PXRD of neat amorphous IMC made by melt quenching that was used as Raman spectroscopy reference sample and for amorphous solubility measurement. 

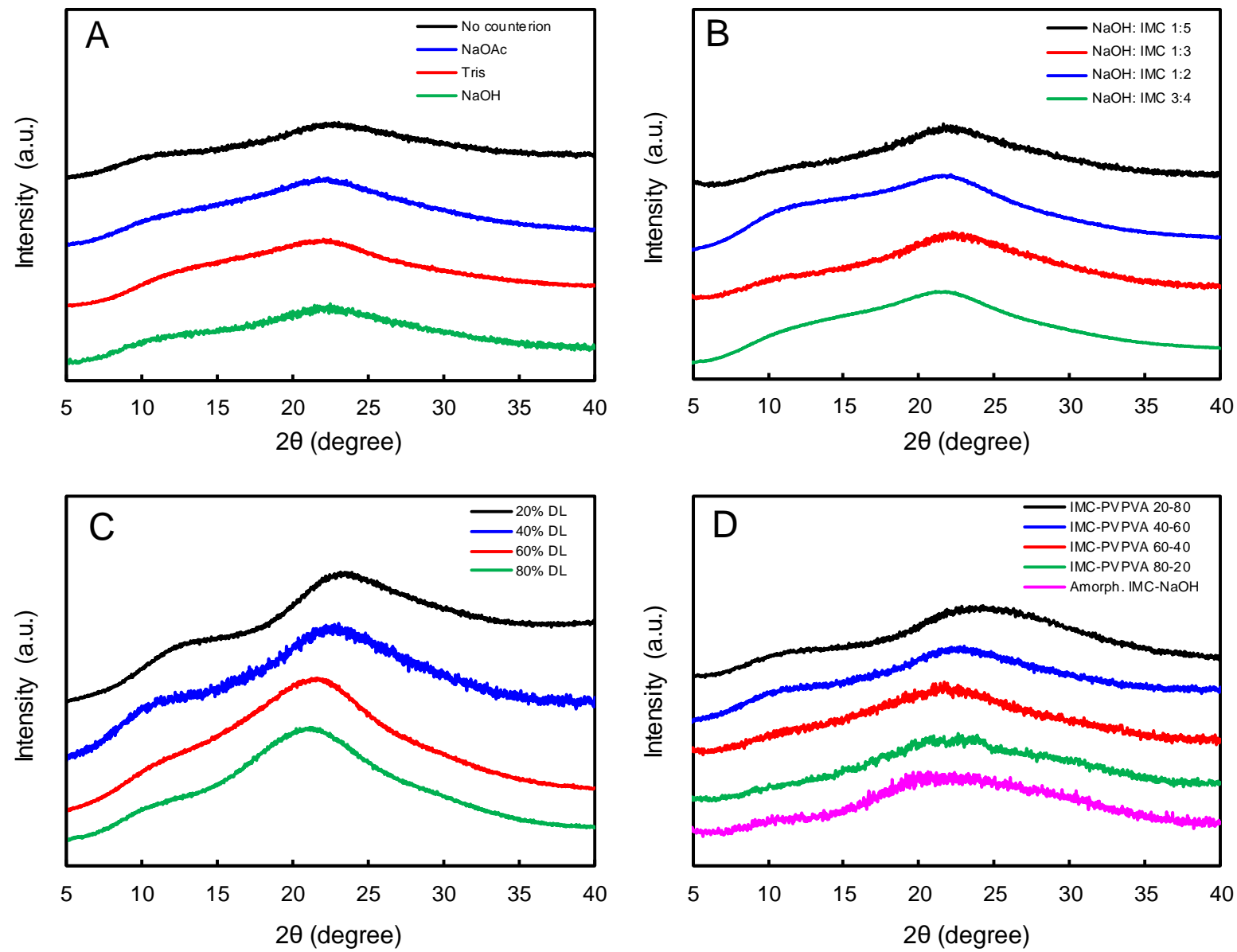

Figure S3. PXRD of surface material scraped after IDR measurement. (A) IMC-PVPVA 40-60 (w/w) ASD containing different bases. The base was at 1:1 molar ratio to IMC. (B) IMC-PVPVA 40-60 (w/w) ASD containing $\mathrm{NaOH}$ at different $\mathrm{NaOH}$ : IMC molar ratios. (C) IMC-PVPVA ASDs at different IMC loadings without counterions. (D) IMC-PVPVA ASDs at different IMC-PVPVA weight ratios with $\mathrm{NaOH}$ at 1:1 molar ratio to IMC. 


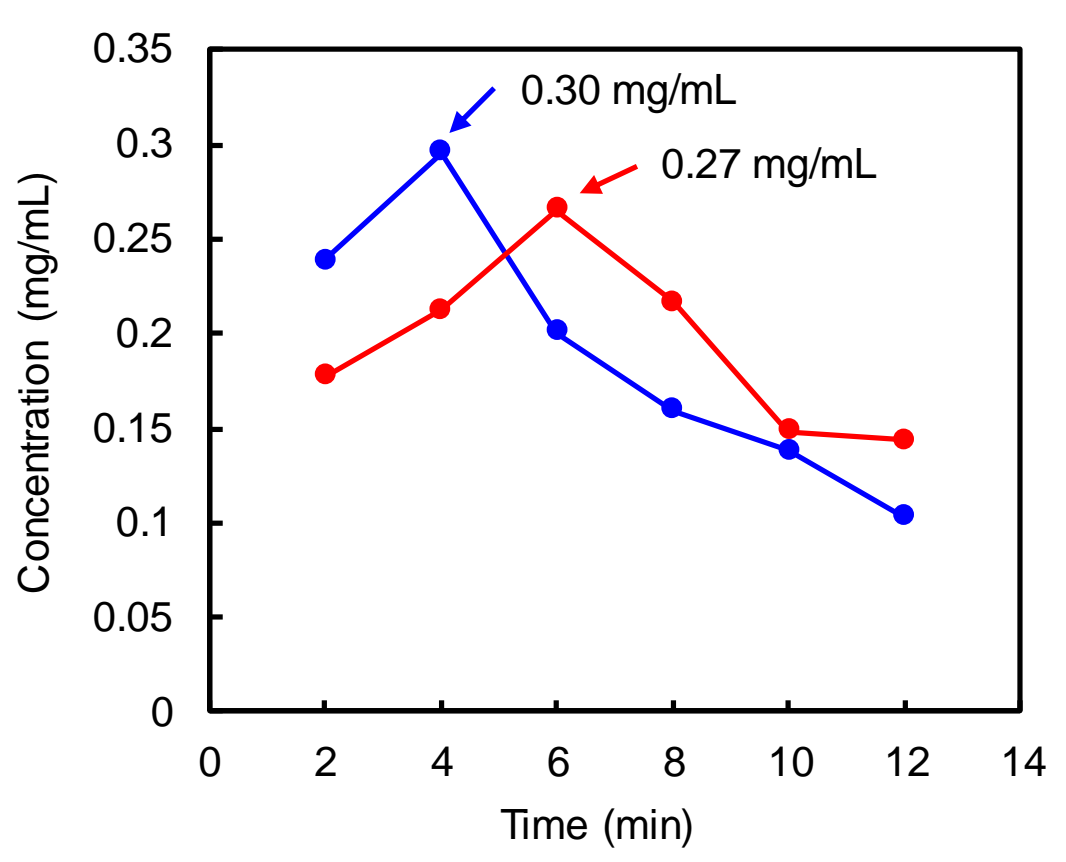

Figure S4. Amorphous solubility measurement of IMC in acetate buffer at $100 \mathrm{mM}$ concentration and $\mathrm{pH}$ $5.55 \pm 0.05$. Desupersaturation occurred before a plateau concentration was reached. The highest achieved concentration $0.30 \mathrm{mg} / \mathrm{mL}$ was treated as the lower bound of amorphous IMC solubility in the buffer. 


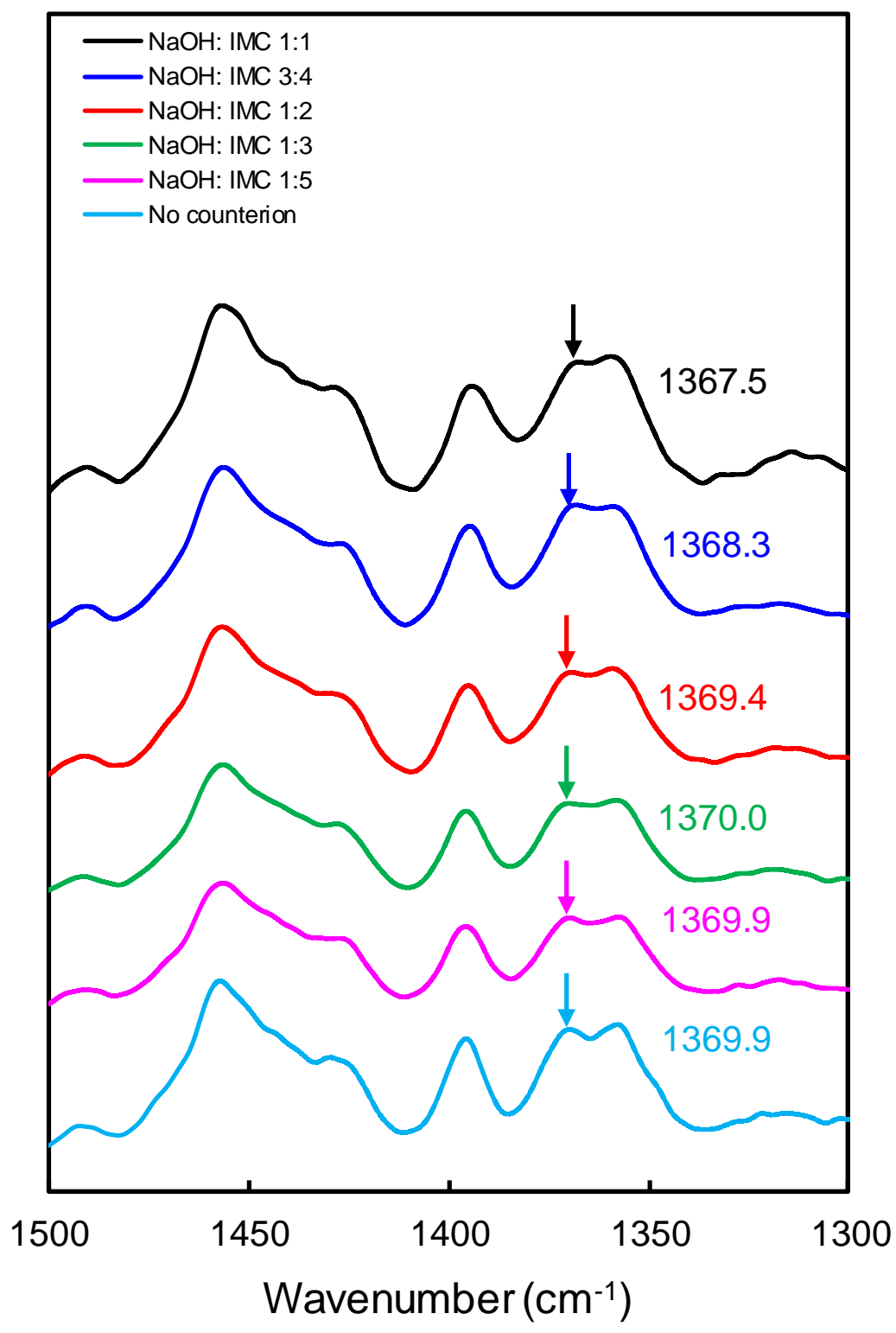

Figure S5. Raman spectra for IMC-NaOH-PVPVA ASDs at different $\mathrm{NaOH}$ to IMC molar ratios. The IMC to PVPVA weight ratio in the ASD was constant at 40:60 while $\mathrm{NaOH}$ to IMC molar ratios varied from 1:5 to 1:1. IMC-PVPVA ASD at 40:60 weight ratio without $\mathrm{NaOH}$ was included as reference. 


\section{Supporting Tables}

Table S1. Composition and IMC weight fraction in IMC-PVPVA ASDs without the addition of base in this work at ca. $1 \mathrm{~g}$ preparation scale. Actual preparation scale varied from 1 to $2 \mathrm{~g}$.

\begin{tabular}{cccc}
\hline IMC to PVPVA weight ratio & IMC weight in ASD (g) & PVPVA weight in ASD (g) & $\begin{array}{c}\text { IMC weight fraction }(x) \text { in } \\
\text { sample }\end{array}$ \\
\hline 20: 80 & 0.20 & 0.80 & $20 \%$ \\
$40: 60$ & 0.40 & 0.60 & $40 \%$ \\
$60: 40$ & 0.60 & 0.40 & $60 \%$ \\
$80: 20$ & 0.80 & 0.20 & $80 \%$ \\
\hline
\end{tabular}


Table S2. Composition and IMC weight fraction in IMC-PVPVA ASDs with the addition of base in this work at ca. $1 \mathrm{~g}$ preparation scale. Actual preparation scale varied from 1 to $2 \mathrm{~g}$.

\begin{tabular}{|c|c|c|c|c|c|}
\hline $\begin{array}{l}\text { IMC to PVPVA } \\
\text { weight ratio }\end{array}$ & $\begin{array}{l}\text { Base to IMC molar } \\
\text { ratio }\end{array}$ & $\begin{array}{l}\text { IMC weight in } \\
\text { ASD (g) }\end{array}$ & $\begin{array}{l}\text { PVPVA weight } \\
\text { in ASD (g) }\end{array}$ & $\begin{array}{l}\text { Base weight } \\
\text { in ASD (g) }\end{array}$ & $\begin{array}{c}\text { IMC weight } \\
\text { fraction }(x) \text { in } \\
\text { sample }\end{array}$ \\
\hline \multirow{8}{*}{$40: 60$} & $\mathrm{NaOH}: \mathrm{IMC}=1: 1$ & 0.40 & 0.60 & 0.045 & $38.3 \%$ \\
\hline & Tris: $\mathrm{IMC}=1: 1$ & 0.40 & 0.60 & 0.135 & $35.2 \%$ \\
\hline & NaOAc: IMC = 1:1 & 0.40 & 0.60 & 0.092 & $36.6 \%$ \\
\hline & $\begin{array}{l}\mathrm{NaOH}: \mathrm{IMC}=1: 1 \\
\text { (Physical mixture of } \\
\text { ASD with } \mathrm{NaOH} \text { ) }\end{array}$ & 0.40 & 0.60 & $\begin{array}{c}0.045 \\
\text { (Externally } \\
\text { mixed with } \\
\text { ASD) } \\
\end{array}$ & $38.3 \%$ \\
\hline & $\mathrm{NaOH}: \mathrm{IMC}=1: 5$ & 0.40 & 0.60 & 0.009 & $39.6 \%$ \\
\hline & $\mathrm{NaOH}: \mathrm{IMC}=1: 3$ & 0.40 & 0.60 & 0.015 & $39.4 \%$ \\
\hline & $\mathrm{NaOH}: \mathrm{IMC}=1: 2$ & 0.40 & 0.60 & 0.022 & $39.1 \%$ \\
\hline & $\mathrm{NaOH}: \mathrm{IMC}=3: 4$ & 0.40 & 0.60 & 0.034 & $38.7 \%$ \\
\hline $20: 80$ & \multirow{4}{*}{$\mathrm{NaOH}: \mathrm{IMC}=1: 1$} & 0.20 & 0.80 & 0.022 & $19.6 \%$ \\
\hline $60: 40$ & & 0.60 & 0.40 & 0.067 & $56.2 \%$ \\
\hline $80: 20$ & & 0.80 & 0.20 & 0.089 & $73.4 \%$ \\
\hline No PVPVA & & 1.00 & 0 & 0.112 & $89.9 \%$ \\
\hline
\end{tabular}

